\title{
Euthanasia for Unbearable Psychological Suffering
}

\author{
An Haekens
}

In recent years one observes in the field of psychiatry a growing proportion of persons requesting euthanasia on account of unbearable psychological suffering. The law concerning euthanasia passed the 17-year mark in 2019 and it is evident today that the number of euthanasias carried out on persons not suffering from a terminal affliction is increasing. In the first (biannual) report of the Federal Commission for the Control and Evaluation of Euthanasia (FCCEE), no mention was made of euthanasia for psychiatric reasons. The report for 2004-2005 ${ }^{1}$ however describes six cases of persons afflicted with psychiatric disorders who were euthanized. The most recent reports number 57 (2018) and 49 (2019) cases. The illnesses cited were depression, bipolar disorders, early stages of dementia, autism, schizophrenia, obsessive-compulsive disorders, posttraumatic stress disorders, borderline type personality disorders, and other personality disorders.

In 2019, polypathology ("the co-occurrence of multiple chronic or acute diseases and medical conditions within one person ${ }^{2}$ ") was the second most frequent diagnosis justifying euthanasia, $17.3 \%$ of the total number of registered euthanasias

\footnotetext{
${ }^{1} \mathrm{http}: / /$ organesdeconcertation.sante.belgique.be/sites/default/files/documents/federale_controle_ en_evaluatiecommissie_euthanasie-fr./14088500_fr.pdf

${ }^{2}$ Definition for the first time used in the report: https://overlegorganen.gezondheid.belgie.be/sites/ default/files/documents/8_euthanasie-verslag_2016-2017-nl.pdf, p. 39.
}

\footnotetext{
A. Haekens $(\bowtie)$

Psychiatrist at the Alexian Brothers Hospital, Tienen, Belgium

e-mail: an.haekens@azt.broedersvanliefde.be
} 
(by way of comparison, in the period of 2012-2013, the proportion was 5.0\%). In the report of the FCCEE for 2016-2017 we read that, even in cases of terminal affliction, $82.8 \%$ of causes for "unbearable suffering" are of a psychic nature, in this case, dependence on care, loss of autonomy, loneliness, despair, feelings of unworthiness, desolation, diminished social contacts, etc. ${ }^{3}$

This evolution reveals a shift that is taking place at the heart of our society. The Dutch psychiatrist Boudewijn Chabot, a pro-euthanasia militant of the first hour, speaks of "a worrisome cultural change regarding self-chosen dying with the doctor's agreement." diktat that has imposed itself in recent years and that "control of the practice of euthanasia has been lost, because the legal requirements — which doctors still master reasonably in cases of somatic illnesses-have been declared applicable without any restriction for vulnerable patients suffering from incurable cerebral illnesses." ${ }^{5}$ Moreover, he observes a link between the growing number of requests for euthanasia and "the financial stripping of care" that undermines the quality of life of persons suffering from a long-term mental illness. More and more critics arise, in our country as well, to voice their reservations regarding the practice of euthanasia.

Starting from a particular case we will first sketch the problem of euthanasia, to then expose, on the basis of legal criteria, the various thorny points of this practice, not only on the form but also on the substance of the practice.

\section{Mrs. Jeanine}

I recently received a telephone call from a colleague in family medicine. He was greatly concerned. A patient he had been treating for a long time and who lived in a residential care center was insistently requesting euthanasia. This situation was disturbing him, since it was not certain that the lady fulfilled the conditions to qualify for euthanasia. Since she would not take no for an answer he had decided to solicit the second opinion of a colleague. That doctor had concluded that in fact the lady did not fulfill the legal conditions for euthanasia. "Case closed." But since the lady was not giving in, and in the face of persistent obstinacy, the family doctor let himself be convinced to consider anew the question of an euthanasia. He called a third doctor for a third opinion. That doctor came to the same conclusion: euthanasia on account of physical suffering was not legally possible in her case. On the other hand, he suggested the possibility of euthanasia on account of unbearable psychological suffering, in light of the patient's suffering caused by her physical decline (poor eyesight, reduced mobility). But to do that required the supplementary opinion of a psychiatrist. That is why the attending doctor was calling me. I found the case doubtful. Yet I sensed how it troubled my colleague and I agreed to visit the lady. She welcomed me cordially and told me why she wanted to die: she was tired of living and expected me to give the green light to her dying. She was imploring my help! I was very touched by her appeal. But was it for me to decide whether or not this woman has the right to die? And was it really a matter of unbearable psychological suffering? I realized very quickly that no way had yet been established to explore or support her psychological

\footnotetext{
${ }^{3}$ https://overlegorganen.gezondheid.belgie.be/sites/default/files/documents/8_euthanasieverslag_2016-2017-nl.pdf

${ }^{4}$ https://www.nrc.nl/nieuws/2017/06/16/de-euthanasiegeest-is-uit-de-fes-11123806-a1563406 ${ }^{5}$ Ibid.
} 
(existential) suffering. In other words, she was absolutely not "beyond treatment." It seemed to me there still were numerous possibilities to make her rediscover meaning to her life, in spite of her limitations. The family doctor reacted to my negative opinion with relief. On the contrary, the people surrounding the patient had strong and negative reactions, giving me the feeling that I had "no compassion whatever," that I was heartless, and that I resolutely lacked empathy. How was I able to refuse this lady in distress the right to die? "Yet that is the purpose of the law, no ...?"

\subsection{What Does the Law Say? ${ }^{6}$}

The law concerning euthanasia stipulates that at the time of his request the patient must be conscious and competent to make a decision. He must be in a medical situation where there is no prospect of improvement. The patient must display constant and unbearable physical and/or psychological suffering that cannot be appeased and that arises from an accidental or pathological affliction that is serious and incurable. His request must be expressed in a voluntary, reflected, and repeated way, and cannot arise from external pressure.

\subsection{A Lack of Prospect of Improvement of the Medical Situation}

In the context of euthanasia by reason of unbearable psychological suffering, the criterion that requires "a lack of prospect of improvement of the medical situation" is already problematic. The description is in fact subject to numerous interpretations. For some, the criterion means "medically incurable," and thus subject to evaluation by the attending doctor: is treatment still possible? For others, the criterion refers to "unbearable suffering" whose evaluation is based on the subjective perception of the patient.

In its recommendations on the requirements for the care to adopt with respect to euthanasia in psychiatry, the Flemish Association of Psychiatry has indicated that there is an urgent need for further specification of the legal criteria for euthanasia for psychological suffering. In those recommendations "no prospect of improvement of the medical situation" is defined as follows: "the affliction is not only serious and incurable but the suffering is also continuous and unbearable and can no longer be relieved. The definition of a lack of prospect of the medical situation does not refer to a patient's subjective experience but to the absence of possibilities for treatment and the incapacity to relieve the suffering in a more objective medico-psychiatric perspective."7

\footnotetext{
${ }^{6} \mathrm{http}: / /$ www.ejustice.just.fgov.be/cgi_loi/change_lg.pl?language $=$ fr\&la=F\&cn=2002052837\&ta ble_name=loi

${ }^{7}$ http://vvponline.be/uploads/docs/bib/euthanasie_finaal_vvp_1_dec.pdf (available in Dutch only).
} 


\subsection{Incurable Disorder}

The law requires an incurable affliction, and thus a situation where no treatment is possible. In a psychiatric context, it is particularly difficult to determine that an illness is incurable. In fact, it is impossible for a psychiatrist to say to his patient, "your disorder is incurable," or "I have enough indications to show the course your illness will take," or again, "science teaches me that your condition will never improve." In psychiatry, it is very difficult to predict the evolution of pathologies and impossible to objectify their incurability. With physical suffering it is altogether different: not that exact prognoses can always be made, but in general, and certainly in the case of cancer, there is enough scientific evidence to ascertain that all treatments have been exhausted or to see what still can be considered. There are a number of psychiatric disorders whose evolution remains unknown. On the other hand, there is no connection between the gravity of a patient's condition and his chances for improvement. Certain people who are in very poor condition for a long time and who have frequent relapses, in spite of many treatments, can get better later. The crux of the matter therefore seems to be that when estimating the incurability of someone's suffering, the subjective factor cannot be eliminated. Even psychiatrists very favorable to euthanasia in case of mental suffering acknowledge that the notion of "incurable illness" can never be fully objectified in psychiatry.... no more than it is possible anyway to describe the suffering unbearable and hopeless on more or less objective grounds. ${ }^{8}$

Healthcare also implies that treatments are available and accessible. This is not necessarily the case in mental health. "The mental health care sector suffers from budgetary thresholds (underfunding, waiting lists), social thresholds (stigmatization, professional recognition), and thresholds having to do with care (for example 'comfort care' is still insufficiently developed) that can result in patients suffering psychiatric afflictions not receiving adequate treatment." ${ }^{\text {[1] }}$.

Confronting questions of euthanasia by reason of unbearable psychological suffering is a new and sometimes confusing phenomenon for psychiatrists. In fact, they have always striven to prevent their patients' suicides, which is anyway what society expects of them. Patients who suffer intensively and who feel hopeless have always talked about their taedium vitae (aversion for life) and spoken these words: "For me, it is not worth the effort." It cannot be overemphasized how much mental suffering can be burdensome for the people afflicted by it and for those around them. Since forever the task of psychiatrists and other caregivers in the psychiatric care sector has been to give the patient the possibility of expressing his wish to die in order to talk about it with him, to carry the suffering of these patients with them, to endure it together, and to help search for "meaning." It involves staying by the patient's side when he cannot go on. It is the job of psychiatrists to deal with one's own sense of powerlessness. All this derives from the following conviction: "It is always

\footnotetext{
${ }^{8} \mathrm{http}: / /$ www.standaard.be/cnt/dmf20171103_03168722

${ }^{9} \mathrm{https} / / /$ www.zorgneticuro.be/sites/default/files/general/Ethisch\%20advies\%2020\%20levenseindezorg\%20psyschisch\%20lijden.pdf (available in Dutch only).
} 
possible. We are not giving up on you." Psychiatrists today are more and more often faced with a wish to die that manifests itself under another form: "I want euthanasia." Society currently expects a psychiatrist, in addition to the continued efforts to prevent as many suicides as possible, to answer his patient's request for euthanasia, and to decide whether his life is still worth living or not. And this with people who are not suffering from terminal illness and who have, in principle, many more years to live.

Concerning euthanasia, in psychiatry, important discussions are nonetheless taking place regarding the handling of the refusal of treatment. What is to be done with a person who is suffering unbearably, for whom treatment is still possible, but who refuses treatment and requests euthanasia? Certain proponents of euthanasia argue that a patient who suffers unbearably, can be treated but who does not feel he has the strength to begin a new treatment, can have access to euthanasia. The question then arises whether the "lack of prospect of improvement of the medical situation" does not come down to the criterion of "the willingness to begin a new treatment" and whether such an application of the law is not an abusive use of it.

The core of the problem resides in the fact that it is impossible to eliminate the "incurability" of an illness. Even psychiatrists very favorable to euthanasia in case of mental suffering acknowledge that the notion of "incurable illness" can never be fully objectified in psychiatry.... no more than it is possible anyway to describe "unbearable and hopeless suffering" on more or less objective bases. ${ }^{10}$

\subsection{Persistent and Unbearable Psychological Suffering}

The criterion of "persistent and unbearable psychological suffering" is not defined by law either. Suffering is by its essence subjective and assessing the suffering of the person concerned can only be subjective, which in turn gives rise to diverse interpretations. It is not easy to define the different forms of suffering. Nonetheless, a distinction needs to be made among inherent suffering, contextual suffering, and meta-suffering.

By inherent suffering, we understand any suffering caused by the pathology itself: the wish to die is in this case a symptom of a psychiatric illness, for example, of depression that leads to despair. Healing from depression will bring the healing of the wish to die. Patients can also suffer from psychotic symptoms, or from inappropriate behaviors linked to an addiction, or from personality disorders.

Next to inherent suffering comes contextual suffering. Patients stricken with serious mental afflictions suffer from the consequences of the disease: the side effects of medication, repeated relapses and hospital admissions, increasing isolation, loneliness, loss of employment, stigmatization, or social regression....

Finally, there is meta-suffering, which is suffering from one's suffering: experiencing the feeling of hopelessness and injustice of having to live with a serious and long-lasting mental illness. Very often it is about existential suffering. We must

${ }^{10}$ www.standaard.be/cnt/dmf20171103_03168722 
dare to admit that we cannot always provide an appropriate answer to this (existential) suffering. Even in mental healthcare, we have made ourselves guilty of therapeutic persistence. It is of paramount importance that caregivers be resolute, reliable, and determined to help the patient and that they stubbornly not abandon the patient. This must not lead to therapeutic persistence: for example, continuous treatment pressure, repeated hospitalizations always proposing more of the same [2].

"Recovery psychiatry" ("Hersteldenken") has already without any doubt contributed to providing solutions to this problem [3]. This approach focuses more on improving the well-being of the patient than on treating the illness. "Recovery appears as a way to live a satisfying life, filled with hope, to contribute to society in a significant way, despite the limitations imposed by illness. Recovery is the origin of a new significance and meaning given to life, all the while overcoming the disastrous effects of a psychiatric illness." 11

In the same way, in psychiatry, palliative care and the care called "crustative" or "oyster" care (care for seriously afflicted psychiatric patients, around whom the healthcare team forms as it were a solid shell or "oyster", within which these persons feel secure $)^{12}$ are paths that need to be further developed, and that can contribute to better care for patients who experience intense psychological suffering.

Moreover, the existential dimension has been neglected for a long time in mental health care [4]. Although caregivers are being involved in the dialogue around the meaning of life, since psychiatric disorders by definition attack the meaning of life, they are not familiar with this existential dimension and are not acquainted with the specific language of the topics related to the meaning of life. Many caregivers feel awkward when they have to deal with them explicitly. However, in recent years we have seen a turnaround. The growing interest in these themes shows an awareness of their importance. There is nonetheless a long road ahead.

In addition, our society shows little inclination to invest more in healthcare for "chronic psychiatric patients": little interest, little scientific research, little funding.... The progressive socialization of mental healthcare, a positive movement, risks leaving aside this category of vulnerable people: they cannot always call on a network of support within society itself and they carry their stigmatization of "psychiatric patient" as a burden. The result is that it is only with great difficulty that they find "their place" in our neoliberal society.

In public debates, the opponents of euthanasia in cases of mental suffering are reproached for lacking respect and empathy for their patients. But what does empathy mean in this specific context? A patient's request to put an end to his life (to put an end to his suffering) can sometimes be understandable to the point that a caregiver is tempted to acquiesce quickly, to comply with it. But do we not give the

\footnotetext{
${ }^{11} \mathrm{http}: / /$ www.ispraisrael.org.il

${ }^{12} \mathrm{http} / / /$ mailsystem.palliatief.be/accounts/15/attachments/NF_12_2016/crustatieve_zorg_geeft_ kwaliteit_van_leven.pdf (available in Dutch only).
} 
patient the message that he no longer has any worth? That we are abandoning him in all his vulnerability and despair? That we cannot take it any longer? Is that really empathy? It would be rather a misleading form and therefore dangerous form of empathy.

\subsection{What Is Empathy?}

The notion of empathy merits some further reflection. Edith Stein [5] established a distinction among different levels of empathy. She makes a difference between being immediately shaken by emotion, "emotional contagion," and "corrective empathy", the evaluation of one's own capacities for empathy. Authentic empathy is only possible when this corrective movement of conscience has been applied. This means that the caregiver will not totally identify with the other person's suffering and will not be supposed to have to act from the patient's point of view, but that he will be able to look truthfully at the other's situation. Only then will he be morally justified to take care of the other person. It is important to be aware of these different levels of empathy, particularly in the context of a request for euthanasia on account of mental suffering.

\subsection{Decision-Making Capacity}

In examining more closely the criterion "the capacity to make a decision" it has to be noted that this criterion has not been specified in the Belgian law concerning euthanasia. Yet, evaluating a person's mental capacity remains a very complicated matter. To this day, there is no consensus on how to evaluate a subject's capacity to make certain specific choices. This difficulty in assessing is still more acute in persons suffering from a psychiatric disorder.

A depression, an anxiety disorder, or a psychotic disorder can alter a person's capacity to make a thoughtful decision, which however does not mean that because of his or her psychiatric affliction the person becomes automatically incompetent for all decisions [6].

\subsection{Conclusion}

Obviously, the legal criteria do not provide sufficient guidance to doctors who wish to evaluate a request for euthanasia in a thoughtful way. The law opens the door to numerous interpretations, as practice confirms. We note that the law is in effect interpreted in very different ways, and in certain cases in a very elastic way.

The law allows any psychiatrist to evaluate very complex psychiatric afflictions, whereas he obviously cannot be an expert in all forms of afflictions, such as autism, eating disorders, mood and personality disorders. 
In practice, we also observe that certain patients shop around for medical assessments: everyone can consult as many doctors as he wishes, until he has garnered enough positive assessments. Scott Kim [7] adds that, from a foreign perspective, it is striking that in Belgium the procedures leading to euthanasia are clearly less strict than for other medical interventions that are however less radical. Moreover, there is no feedback loop in this domain: it is not possible to draw any lesson from one's errors, since the patients can no longer speak, being deceased.

The problem, in any event, does not arise solely from the law, but equally from the system of control and evaluation, which in our country functions little or not at all. After 17 years and about 18,000 files submitted to the Federal Commission for Control and Evaluation, only one case was sent to the prosecutor. Nor has any interpretation of the data been made or case descriptions published. Lastly, no close evaluation of the commission's operation has ever taken place.

What should we conclude from this? Without wanting to minimize the immeasurable suffering of many patients afflicted with a psychiatric disorder, the current evolution, where requests for euthanasia by reason of psychological suffering are more and more frequent, is a matter of concern. From the viewpoint of the caregiver, it is sometimes "tempting" to quickly acquiesce to this request. Indeed, it is not easy to deal with one's own feelings of powerlessness in the face of so much suffering in the other person, and it is difficult not to give in to despair.

Requests for euthanasia seem to flourish in the current context of society. We can in fact perceive a general change in culture. "Each must be able to decide for himself when he has had enough" seems to have become the new standard of normality. Such a shift is definitely taking place amount the elderly, as shown in the current debates on "life fatigue" and "completed life".

The social context has a determining effect on patients with a psychiatric disorder. Given that our society is evolving toward a society where every vulnerable life is considered unworthy of human dignity (old age, dependence on care, dementia, mental illness, Down's syndrome....), it becomes extremely difficult to give meaning to one's own life once one is suffering a serious psychiatric disorder. The observation that psychological suffering increasingly plays a role in the practice of euthanasia and that this psychological suffering is a consequence of dependency on care, loss of autonomy, loneliness, loss of dignity, or loss of the ability to maintain social contacts, confirms this evolution.

Is not the primary mission of our society to first invest in quality care, in innovative and accessible treatments, in developing "recovery psychiatry," in organizing palliative care and "oyster" care for the most vulnerable patients with a psychiatric disorder? And above all to give them a place in our society?

\subsection{The Long and the Short of Mrs. Jeanine's Story}

A few months after my visit with Mrs. Jeanine as "third expert" quite by chance I learned that her partner, with whom she had had a long "LAT" relation (Living Apart Together) had passed away. This man had kept many secrets to himself and had always expressed the wish to die after his companion. When he felt, and then knew that his last days were upon him 
and that he would no doubt be the first to die, he pressured his companion to request euthanasia so that their agreement regarding their dying might be upheld. After all, he had many secrets on a relational level, and he did not want those secrets to be revealed if he died first....

\section{References}

1. Vandenberghe J. Euthanasie bij ondraaglijk lijden als gevolg van een ongeneeslijke psychiatrische aandoening. In: Delepeleire J, editor. Euthanasie en menselijke kwetsbaarheid. Leuven: KU Leuven Metaforum; 2013. p. 39-51.

2. Haekens A, Hermans J. Geen Eind aan mijn pijn? Over uitzichtloos psychisch lijden. Antwerpen/Apeldoorn: Garant; 2008. p. 11.

3. Callebert A. Herstel als antwoord op euthanasie? Acco; 2018.

4. VanPraag HM. Zinverlies, een verwaarloosd onderwerp in de psychiatrie. Tijdschrift voor Psychiatrie. 2010;52(10):7050714; available (in Dutch only) via webpage: http://www.tijdschriftvoorpsychiatrie.nl/en/issues/432/articles/8293.

5. Stein E. On the problem of empathy. Stein W (Trans.) Washington: ICS Publications; 1989.

6. Haekens A. Beslissingsbekwaamheid in de gerontopsychiatrische context. Leuven: University Press; 1998.

7. Kim S, DeVries R, Peteet J. Euthanasia and assisted suicide of patients with psychiatric disorders in the Netherlands 2011 to 2014. JAMA Psychiat. 2016;73:362-8.

Open Access This chapter is licensed under the terms of the Creative Commons Attribution 4.0 International License (http://creativecommons.org/licenses/by/4.0/), which permits use, sharing, adaptation, distribution and reproduction in any medium or format, as long as you give appropriate credit to the original author(s) and the source, provide a link to the Creative Commons license and indicate if changes were made.

The images or other third party material in this chapter are included in the chapter's Creative Commons license, unless indicated otherwise in a credit line to the material. If material is not included in the chapter's Creative Commons license and your intended use is not permitted by statutory regulation or exceeds the permitted use, you will need to obtain permission directly from the copyright holder.

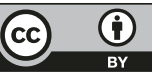

